\title{
Research on the Path and Mechanism of Smart City Construction from the Perspective of New Infrastructure
}

\author{
Ya lian $\mathrm{Du}^{1 *}$ \\ ${ }^{1}$ School of Finance and public administration, Harbin University of Commerce, Harbin, Heilongjiang 150028, China \\ *Corresponding author. Email: $1920168210 @$ qq.com
}

\begin{abstract}
After the 21 st century, driven by the development of digital economy, cloud computing, 5G, artificial intelligence technology and new infrastructure policies, the construction of smart cities in China has also ushered in a period of rapid development. Since the outbreak of pneumonia in COVID-19, the prevention and control of smart cities have played an important role. Based on the current situation and importance of the development of smart cities, this paper expounds the importance of building smart cities. From the perspective of "new infrastructure" accelerating the development of smart cities, this paper explores the path and mechanism of smart city construction from the perspective of new infrastructure from three aspects: synchronous development of new consumption and new infrastructure, synchronous development of new consumption and new infrastructure, and coordination between new infrastructure and new layout.
\end{abstract}

Keywords: New Infrastructure, Smart City Construction, Path and Mechanism

\section{THE CONCEPT OF "NEW INFRASTRUCTURE"}

"New infrastructure" is put forward on the concept of "old infrastructure", which is different from people's common understanding of repairing bridges and paving the way for building houses. "New infrastructure" refers to new infrastructure, which is an infrastructure system guided by new development concepts, driven by technological innovation, based on information networks, facing the needs of high-quality development, and providing services such as digital transformation, intelligent upgrading, integration and innovation. The "new infrastructure" is essentially the infrastructure of digital information. According to various media reports, the "new infrastructure" mainly includes seven major areas: 5G infrastructure, UHV, intercity high-speed railway and urban rail transit, charging piles for new energy vehicles, big data centers, artificial intelligence and industrial Internet. As early as 2018, the country defined the positioning of "new infrastructure construction" such as $5 \mathrm{G}$, artificial intelligence and industrial Internet. As a major change point in the field of mobile communication, $5 \mathrm{G}$ is the leading field of "new infrastructure" at present[1]. Before that, 5G has been set as "new kinetic energy of economic development" by high-level officials, and the construction of smart cities cannot be separated from the support of "new infrastructure

\section{OVERVIEW OF SMART CITY DEVELOPMENT}

\subsection{Development Status of Smart City}

According to the statistics of the United Nations and the World Bank, from 1960 to 2019, the world's urban population increased from 1.019 billion to 4.274 billion, and the level of global urbanization continued to improve. From $33.6 \%$ in 1960 to $55.7 \%$; In the future, the global urbanization process will continue to accelerate. The United Nations report "World Urbanization Trends in 2018" predicts that the global urbanization rate is expected to reach $68.4 \%$ in 2050 , and nearly $70 \%$ of the world population will live in cities. The improvement of urbanization process has brought severe challenges to urban economic development, resource utilization, ecological environment and quality of life. In order to meet a series 
of challenges of urban development, realize long-term sustainable development, build a smart city development system, and improve scientific decision-making level and refined management efficiency, it has become the first choice for more urbanized managers[2].

\subsection{Importance of building a smart city}

The sudden epidemic makes the construction of smart city face a great test. In some cities with good implementation of smart city construction, information technologies such as Internet, big data, 5G and artificial intelligence have been used to improve the refined and intelligent level of urban governance and management, and successfully provided effective assistance for the epidemic situation. However, most of the facilities related to smart cities have been paralyzed in this epidemic prevention war, which exposes the shortcomings of weak infrastructure and "data islands" in the construction of smart cities in China. In the future, it is necessary to continue to explore effective ways to improve the scientific governance level of smart cities and enhance the digital management ability of smart cities.

\section{3."NEW INFRASTRUCTURE" ACCELERATES THE DEVELOPMENT OF SMART CITIES}

The concept of "new infrastructure" originated from "new infrastructure construction" proposed by the Central Committee. According to the National Development and Reform Commission, the new infrastructure is an infrastructure system that is guided by new development concepts, driven by technological innovation, based on information networks, oriented to the needs of high-quality development, and provides services such as digital transformation, intelligent upgrading, and integration and innovation. Cities are the core carriers of infrastructure construction, so the relationship between smart cities and new infrastructure construction is inseparable. Smart city is an important demand area for realizing the value of new infrastructure, and new infrastructure is an important driving force for the construction of smart city.

The "new infrastructure" accelerates the development of smart cities in the following three aspects. First, there is huge room for the market scale of new infrastructure in various fields to rise. At present, there is still huge room for growth in the market scale from the investment scale of seven important new infrastructure areas, namely $5 \mathrm{G}$ base stations, data centers, industrial Internet, artificial intelligence, charging piles, UHV, high-speed rail and urban rail transit. Second, "new infrastructure" is the foundation of digital economy, and digital economy is the core kinetic energy of economic development. Digital economy is a new kinetic energy for China's economic development. In 2019, the added value of China's digital economy reached 35.8 trillion yuan, accounting for $36.2 \%$ of GDP, which increased by 1.4 percentage points year-on-year. The growth rate of China's digital economy was significantly higher than that of GDP in the same period for several years. At the same time, the contribution rate of digital economy to GDP growth reached $67.7 \%$ in 2019 , which is the core key force driving economic development. Developing "new infrastructure" means developing digital economy, which is composed of "digital industrialization" and "industrial digitalization". The former refers to the added value of the information industry and corresponds to the "information infrastructure" of the "new infrastructure"; The latter refers to the contribution of new technologies to other industries, and corresponds to the "integrated infrastructure" of "new infrastructure". Third, under the new infrastructure, the construction of smart cities has an opportunity to upgrade in an all-round way. The proposal of new infrastructure will reconstruct the development logic of smart cities from the technical and strategic levels. For the development form of smart cities, on the one hand, new infrastructure will accelerate the process of industrial digital economy of cities; On the other hand, it can improve the city format and service supply.

\section{CONSTRUCTION PATH OF SMART CITY FROM THE PERSPECTIVE OF NEW INFRASTRUCTURE}

\subsection{Promote the simultaneous development of new consumption and new infrastructure in smart cities}

Promoting consumption and investment is an extremely important measure to improve economic growth, and building a smart city is inseparable from the promotion of consumption growth and investment. According to the Bank of China Research Institute, the total investment in the field of "new infrastructure" in 2021 is as high as 1.3 trillion yuan, which means that the construction of smart cities has become the only way for urban construction in the new era. However, blind investment, if not supported by corresponding consumption, will make a good cycle of economic growth a dead letter, and may even lead to a waste of investment. The development of new infrastructure is bound to be accompanied by new basic investments such as new energy and high technology. To form such a basic investment, it needs to be supported by consumption to play the role of new infrastructure. Therefore, to promote the simultaneous development of 
new consumption and new infrastructure in smart cities, it is necessary to establish and improve new consumption scenarios, such as promoting cloud computing into people's daily life, vigorously developing $5 \mathrm{G}$ online education, 5G lifestyle, new energy vehicles and so on. Secondly, the government formulates certain economic policies to stimulate the consumption of new infrastructure, such as giving certain economic compensation to users who use new energy vehicles, drawing lessons from the construction of smart cities in other countries, forming the consumption level of smart cities with Chinese characteristics, doing a good job of publicity, and efficiently solving the "last mile" problem of citizens, so as to implement the new consumption and new infrastructure of smart cities.

\subsection{Promote the new governance of smart cities and the same frequency resonance of new infrastructure}

The 2018 World Urbanization Outlook Report released by the United Nations Department of Economic and Social Affairs predicts that the global urban population will increase by 2.5 billion by 2050 . Among them, China will increase its population by 255 million. Problems brought about by the ever-expanding population are coming in one after another. For example, traffic congestion and the continuous deterioration of the environment have become urgent problems to be solved in front of the city. Besides, there are the problems of unbalanced development and insufficient allocation of resources, all of which pose new challenges and new requirements for the construction of smart cities. Under the background of new infrastructure, taking 5G, digital economy and artificial intelligence as the development basis, it provides fresh blood for the development of smart cities.

To build a smart city under the background of "new infrastructure", we must first strengthen the construction of a smart middle platform, which is the core layer of a smart city and the foundation of a smart city, including the link between many smart cities such as technology layer, data layer and service layer. The formation of "data island" can be avoided only by fully enhancing the construction of the intelligent middle platform. Through this intelligent middle platform, the integration of business, data and services in various fields can be promoted efficiently and intelligently. There should be only one wisdom middle office, and there cannot be multiple data middle offices in a city. If a country cannot have multiple ruling parties at the same time, it is easy to have excessive data load, different decrees and unable to be uniformly controlled. During the new crown epidemic, there were many intelligent middle schools in the process of building smart cities in many countries, which directly led to difficulties in centralized control and lack of efficient prevention and control, which led to the outbreak out of control. With the development of digital economy, cloud computing and $5 \mathrm{G}$, smart cities have already possessed the ability and level to build a unified command center. With the empowerment of new infrastructure and new technology, big data can be processed quickly, and standardized data can be formed and output through procedures in the intelligent middle platform. These data can form a strong grasp when building a smart city, provide the most valuable resources for city managers and bring greater benefits to citizens[5]. It is no exaggeration to say that the establishment and perfection of wisdom middle platform can greatly improve the level of urban governance and make people's daily life more convenient

Water can carry a boat and overturn it. Smart China brings convenience to smart cities, but it also needs to establish a governance mechanism. Only by establishing a new management model adapted to smart cities, constantly meeting the needs of urban citizens, making the new infrastructure play a better role, and guiding the rational dispatch and allocation of urban resources by using the smart middle platform, can good collaborative communication be formed between departments. This requires the new governance and new infrastructure of smart cities to resonate at the same frequency, so that smart cities can exert their maximum efficiency.

\subsection{Promote the coordination of new infrastructure and new layout in smart cities}

The layout of a city is the epitome of a city's development level, which can be seen to a certain extent. Driven by the new infrastructure, the economic development, economic transformation and upgrading of cities in China have been greatly improved. Since the beginning of this year, many provinces in China have promoted many key investment projects around the new infrastructure, including manufacturing, new energy machinery products, logistics, e-commerce and so on. By April 2020, the number of pilot projects related to smart cities identified by the Ministry of Science and Technology, the Ministry of Industry and Information Technology and the National Development and Reform Commission has reached 749 . This data can fully prove that the country is paying more and more attention to the coordinated development of new infrastructure and smart cities. Therefore, under the background of new infrastructure, it is the most important thing to do a good job in the layout of smart cities. First, we need to do a good job in the regional layout of smart cities under the new infrastructure. In the eastern part of China, where the level of economic development is relatively high, it is necessary to vigorously strengthen the leading role of demonstration led by new technologies, actively explore new models and schemes to adapt to the development of smart cities, and provide technical support and 
demonstration for other underdeveloped areas. The central region with an average level of economic development should strive to mobilize its supporting role, give full play to its regional role of connecting east and west, increase efforts to develop new infrastructure construction bases, provide "product" support for the eastern and western regions, and develop the backward western regions. It is necessary to combine the advantages of this region and "attract" new production factors such as data and information according to local conditions. Secondly, efforts should be made to improve the investment layout of smart cities under the new infrastructure[6]. In terms of investment subject, considering that the new infrastructure has strong market application value and scientific and technological content, it is necessary to insist on market investment, create investment schemes and modes needed by the market, and use artificial intelligence, big data and digital economy to invest in the layout mode, so as to make smart cities smarter.

\section{CONCLUSION}

The report of the 19th National Congress clearly stated that "Digital China, Smart Society" should be built. With the continuous expansion of China's urban population and the acceleration of urbanization, the construction of smart cities has become the only way for urban construction, and the widespread COVID-19 epidemic has brought about a new revolution in China's infrastructure. It is worth mentioning that under the background of new infrastructure, the construction of smart cities is not achieved overnight. It promotes the simultaneous development of new consumption and new infrastructure in smart cities, promotes new governance and new infrastructure in smart cities to resonate at the same frequency, and promotes new governance and new infrastructure in smart cities to resonate with Ren Zhong at the same frequency. This needs to be based on scientific assessment, give more consideration to the needs of residents, urban management and the environment, and find a balance between the needs of stakeholders in order to achieve a balance between supply and demand and promote the sustainable development of cities.

\section{REFERENCES}

[1] Ye Zi, Yuan Miaomiao. It turns out that smart life is so close to us [N]. People's Daily Overseas Edition, 2018-09-11.1

[2] In the ninth collective study of the Political Bureau of the CPC Central Committee, $\mathrm{Xi}$ Jinping emphasized strengthening leadership, making plans, clarifying tasks and laying a solid foundation to promote the healthy development of the new generation of artificial intelligence in China [N]. People's Daily, 2018-11-01.

[3] Liu Ming. Practice and Thinking of Suzhou Smart City Construction [J]. Suzhou Party School, 2017

[4] Zhou You, Chen Jianfeng. Establishment and application of road engineering model based on BIM technology $[\mathrm{J}]$. Highway Traffic Technology, 2018,34(3):29-32,38.

[5] Gong Haixia, Wang Mingzhi, Gu Lina. Analysis of the research status of personalized information service based on bibliometrics [J]. Information Science, 2011(3):391-395.

[6] NUNO L, ANTHONY J V. Infrastructure, Geographical Disadvantage, Transport Costs, and Trade[J]. World Bank Economic Review, 2001(3): 451-479. 